\title{
Root canal morphology of Mandibular premolars in Patients from Asir Region in Saudi Arabian Population
}

\author{
Adel Al Obiad ${ }^{1}$, Suheel Manzoor Baba ${ }^{2}$ \\ ${ }^{1}$ Assistant Professor, Department of Restorative Dental Sciences, College of Dentistry, King Khalid University Abha \\ ${ }^{2}$ Associate Professor, Department of Restorative Dental Sciences, College of Dentistry, King Khalid University Abha
}

\begin{abstract}
Knowledge of the root canal morphology and the possible anatomical variations of mandibular premolars are important for the successful endodontic treatment. The aim of this study was to evaluate the variation in morphology of root canals in mandibular premolars in patients from asir region of Saudi arabia. Methodology: One hundred and ten human mandibular premolars (36 first premolars and 74 second premolars) from patients requiring endodontic treatment were involved in this study. After access the cavity of the teeth, the root canals were explored and radiographs were taken. Results: Premolars with one canal were found in 910 f cases (30\% first premolar and $61 \%$ second premolar) and premolars with two canals were found in $8 \%$ of cases (3\% first premolar and $5 \%$ second premolar). There was just one case (1\%) where a first premolar had three canals. These differences were statistically significant with $P<0.05$. Conclusion: Clinicians should be aware of the root canal variation in the mandibular premolars and be able to apply this knowledge in radiographical and clinical interpretation.
\end{abstract}

Keywords: Morphology, endodontic, premolars, Radiographs.

\section{Introduction}

The main objectives of root canal treatment are thorough shaping and cleaning of all pulp spaces and its complete obturation with an inert filling material. The presence of untreated canals may be a reason for failure of endodontic therapy.

Therefore, it is essential for clinicians to have knowledge about root canal configurations although its morphology varies largely in different ethnicities and even in different individuals with the same ethnic ${ }^{1}$. The root canal configuration is usually complicated. Based on the literature in addition to ethnicity, age and gender also can influence these diversities ${ }^{2,3}$.

Mandibular first and second premolars are typically described as single rooted teeth with ovoid roots in cross sections and developmental concavities on mesial and distal aspects of the roots surfaces. Several studies indicated high level of endodontic failures and flare-ups due to complexity and diversity of root canal configurations in mandibular premolars ${ }^{3,4}$

The mandibular first premolar with dual canals dividing at various levels of the root can generate complex mechanical problems. The canals may divide almost anywhere down the root. Because of the absence of direct access, cleaning, shaping, and filling of these teeth can be extremely difficult ${ }^{5}$.

A study by Vertucci and Francois 1986 revealed that the mandibular first premolar had one canal at the apex in $74.0 \%$ of the teeth studied, two canals at the apex in $25.5 \%$, and three canals at the apex in the remaining $0.5 \%$ of the teeth. Only $12 \%$ of mandibular second premolars studied had a second or third canal. They also showed that the second premolar had one canal at the apex in $97.5 \%$ and two canals at the apex in only $2.5 \%$ of the teeth studied ${ }^{2}$.

This study aimed to investigate the difference in the number of root canals in first and second mandibular premolars in patients from Asir region

\section{Methodology}

This study was conducted in college of dentistry king khalid university abha Saudi Arabia. A total of 110 mandibular premolars (36 first and 74 second premolars) requiring Endodontic treatment from patients in asir region were included in the study. 2 radiographs in different angulation were taken to access the morphology of each tooth. Two independent Endodontists assessed the number of roots and canals, the position where canal bifurcation occurred and the canal configuration to reach consensus on the interpretation of radiographic findings. After rubber dam application an endodontic access cavity was made with round bur. Oval shaped access cavity was prepared which extended buccally up to the tip of buccal cusp, lingually up to lingual cusp inclination, walls were diverged occlusally with No. 2 Endo Access bur (Maillefer, Dentsply, Switzerland) for better visualization of the orifices Working length were confirmed with both an $\mathrm{x}$ ray and apex locators. Canals were instrumented and obturated with gutta-percha. A post operative x-ray was taken to assess the quality of obturation.

\section{Results}

There were differences in the shape of the canals and in the number of these canals of the mandibular premolars investigated. Premolars with one canal were found in $91 \%$ of cases and premolars with two canals were found in $8 \%$ of cases. There was just one case $(1 \%)$ where a first premolar had three canals. 
International Journal of Science and Research (IJSR)

ISSN (Online): 2319-7064

Index Copernicus Value (2015): 78.96 | Impact Factor (2015): 6.391

\begin{tabular}{|c|c|c|}
\hline $\begin{array}{c}\text { Number of } \\
\text { canals }\end{array}$ & $\begin{array}{c}\text { First premolar } \\
(\mathrm{n}=36)\end{array}$ & $\begin{array}{c}\text { Second premolar }(\mathrm{n} \\
=74)\end{array}$ \\
\hline One canal & 32 & 68 \\
\hline Two canals & 3 & 6 \\
\hline Three canals & 1 & 0 \\
\hline
\end{tabular}

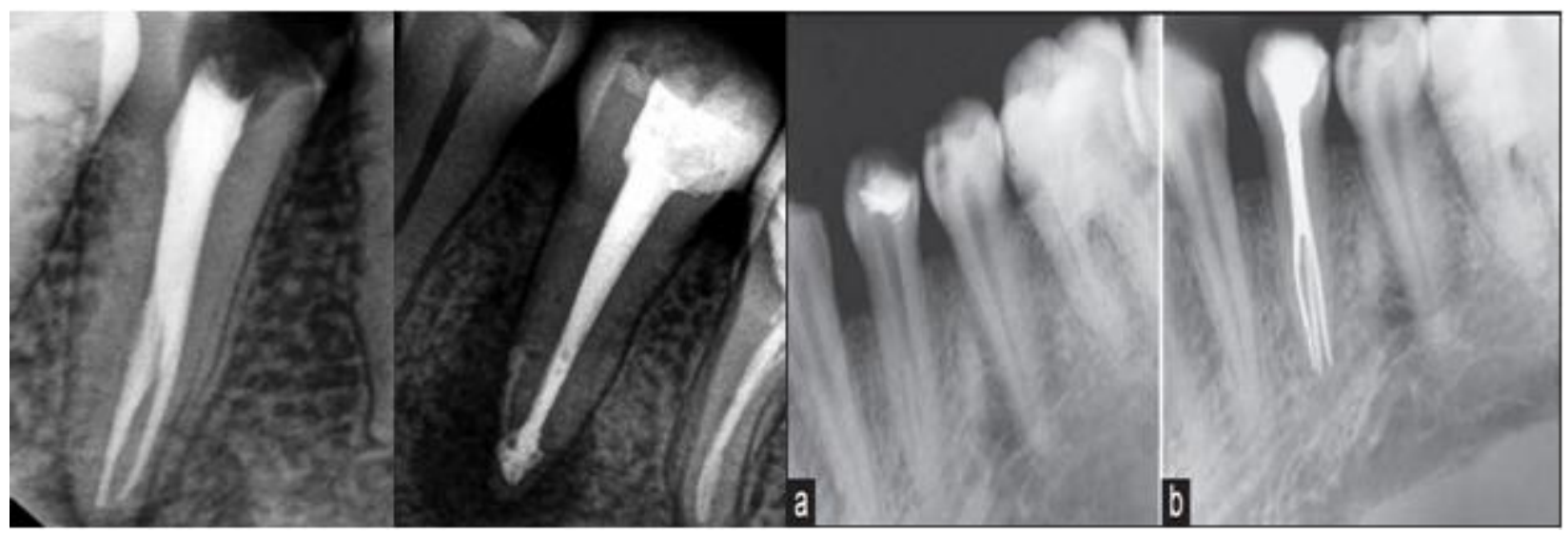

\section{Discussion}

Knowledge of basic root and root canal morphology as well as possible variation in anatomy of the root canal system is important in achieving successful nonsurgical root canal treatment. This is followed by negotiation, cleaning and shaping, and obturation of the entire canal system in 3 dimensions. Variation in root canal morphology was suggested as the most likely reason for the high frequency of endodontic flare-ups and failures.

Many studies of the root and canal morphologies of mandibular premolars have been conducted because these teeth can present with complex morphologies that often complicate treatment. The majority of these studies have involved complete destruction of the tooth during examination (e.g., hard tissue sectioning). This study was done on patients requiring endodontic treatment of mandibular premolars. $6,7,8$

The results of this study revealed that $88.89 \%$ of the mandibular first premolars exhibited single canals (Type I). This proportion is higher than those reported in many previous studies. $^{7,8}$ The results of this study revealed that $91.89 \%$ of the mandibular second premolars exhibited single canals. This proportion is lower than those that have been reported in many previous studies,but this proportion is greater than that reported by Sert and Bayirli ${ }^{6,7,8,9}$.

Mandibular first premolar with 2 canals was found in 8.33 cases and mandibular second premolars with 2 canals were found in $8.11 \%$ cases. There was only one case in mandibular first premolar which had 3 canals.

A great deal of variation has been reported in the literature with respect to the root and root canal morphologies of teeth, and the human mandibular premolar is no exception. This variation in the internal canal morphology of the human mandibular premolar might be attributed to hereditary and ethnic differences ${ }^{8,9}$.

\section{Conclusion}

Within the limitations of this study, the root canal morphology of mandibular premolars in Saudi Arabian population was, in general, comparable to that of other populations. The dental practitioners should have a sound knowledge of common anatomy of permanent teeth and its possible variations and use the available tools to locate and treat the whole root canal system to ensure a successful treatment outcome.

\section{References}

[1] Cleghorn BM, Goodacre CJ, Christie WH. Morphology of teeth and their root canal systems. Endodontics. 6th ed. Hamilton Ontario, Canada: BC Decker; 2008. 151

[2] Vertucci FJ. Root canal anatomy of the human permanent teeth. Oral Surg, Oral Med, Oral Pathol. 1984; 58(5):589-99

[3] Chourasia HR, Meshram GK, Warhadpande M, Dakshindas D. Root Canal Morphology of Mandibular First Permanent Molars in an Indian Population. Int J Dent. 2012:2012.

[4] Geider P, Perrin C, Fontaine M. [Endodontic anatomy of lower premolars--apropos of 669 cases] J Odontol Conserv. 1988;(10):11-5.

[5] Prabhu N, John R, Munshi A. Aberrant root development of the mandibular premolars: a case report. J Paediatr Dent. 1999; 9(1):49-51.

[6] Sert S, Bayirli GS. Evaluation of the root canal configurations of the mandibular and maxillary permanent teeth by gender in the Turkish population. J Endod. 2004;30(6):391-8.

[7] Llena C, Fernandez J, Ortolani PS, Forner L. Cone-beam computed tomography analysis of root and canal morphology of mandibular premolars in a Spanish population. Imaging Sci Dent. 2014; 44(3):221-711.

[8] Yu X, Guo B, Li K-Z, Zhang R, Tian Y-Y, Wang H, Tao HD. Cone-beam computed tomography study of root and canal morphology of mandibular premolars in a western Chinese population. 2012;12(1):18.

[9] Rahimi S, Shahi S, Yavari HR, Manafi H, Eskandarzadeh N. Root canal configuration of mandibular first and second premolars in an Iranian population. J Dent Res Dent Clin Dent Prospects. 2007;1(2):59 